trees, Koenig yells, "Hello?" in a specific, drawn-out vocal tone towards nest holes to get a bird to peer out. "I'm sure that it has to have that particular nasal quality to get them to look out," jokes Koenig. Catching the adult birds is a feat that involves climbing a tree, setting an ambush to trap the birds inside the cavity and sawing a new entrance from which to carefully remove them. "It's something of an art form," says Koenig.

So, when he triumphs, Koenig performs his second ritual, both as a celebration and as a quirky benediction for the bird's continued health. "When I finish banding and measuring them, I kiss them on the head and say, 'Live long and prosper."

He has passed the rituals on to junior researchers as a symbolic way of sharing his successes, and says that he would be disappointed if they failed to repeat his speeches. "You hope that your little rituals will make it work the next time round," he says. "I do indeed show them and claim, only partly tongue-in-cheek, that such things are important to the project."

For his part, Davis carries a personal totem in his pocket - a replica of a 13,000-year-old spear point - to remind him how luck led to the discovery of the original.

On a field trip to Idaho in 1997, he accidentally used the wrong compass setting, and so incorrectly laid a baseline that shifted his field site. That mistake uncovered a pit loaded with stone tools and spear points. It was an incredible find that documented the technologies of some of the earliest hunter-gatherers in North America. "If I had not set the line wrong," Davis says, "we would have missed it."

A collaborator of Davis's, Dennis Jenkins at the University of Oregon in Eugene who also studies North America's earliest inhabitants, always dons his lucky field hat before entering a work site, and takes it off when he leaves in the evening. He also considers his bright orange, multi-pocket field vest and the buck knife that hangs from his belt indispensable items that support his field 'persona', which he says helps him to lead students through dicey situations.

Xygalatas says that charms and rituals might offer some people a sense of stability or control when dealing with the erratic nature of experiments and science. "We know the world is a very chaotic place, and we have no control over most of it. But we can trick ourselves," he says.

Kendall Powell is a freelance writer in Boulder, Colorado.

1. Wood Brooks, A. et al. Organ. Behav. Hum. Decis. Process. 137, 71-85 (2016).

2. Lang, M. et al. Curr. Biol. 25, 1892-1897 (2015).

3. Nishikawa, T. \& Morishita, N. Exp. Anim. 61, 177-181 (2012).

COLUMN

\title{
Tackling bias head on
}

\section{We need a new normal for women, says Shari L. Gallop.}

A $s$ an early-career female researcher in coastal geoscience and oceanography, I was surprised by the level of gender inequality that I encountered once I'd finished my $\mathrm{PhD}$ and landed an academic post as a lecturer.

I had my eureka moment in 2015, just after starting my lectureship at Macquarie University in Sydney, Australia. When I looked at the committee of a major international coastalgeoscience conference that I was planning to attend, I saw that not one of its 12 members was a woman.

I have had enough of the lack of women as keynote conference speakers in the discipline, or as editorial-board members for related journals. I am tired of often being the only female speaker at a conference session or the only woman working on a collaborative project.

I can easily name at least ten people who have been (and are) instrumental in my career. Of these, eight are male and only two are female. And although a couple of my close collaborators in my field are women, I'm probably unusual in that respect. I cannot think of one woman in my immediate research area who is a professor, or who is older than about 50 .

We need a 'new normal'. And some of my colleagues and I are working to create one.

\section{BUILD A NETWORK}

I started talking with female colleagues about this issue in 2015, and found that we all wanted to see change. Gender bias in science is not selfcorrecting. So, in 2016, we founded Women in Coastal Geoscience and Engineering (WICGE), an international network with a growing membership of more than 200 and hundreds of additional supporters on our social-media platforms. We aim to inspire, support and celebrate women at all stages of their careers through networking, mentoring and pushing for equal representation and opportunities.

We launched WICGE in March 2016 at the International Coastal Symposium, a key biennial conference in our discipline. We didn't know where this journey would lead us, only that we needed to do something. A discussion panel at the launch made it clear that identifying and combating gender bias was important to everyone in our discipline.

We also learnt that many women face the same daily manifestations of gender bias, such as being ignored in favour of male colleagues, receiving fewer invitations to write grants or having fewer opportunities to do field work after becoming parents. Not surprisingly, many

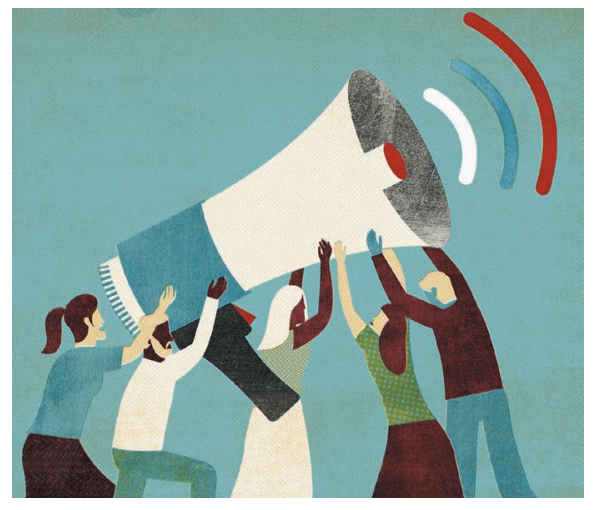

women have chosen to leave the discipline.

WICGE's online presence is raising the profiles of women in our discipline. We have been running events at regional and international conferences to promote awareness of gender bias, and this year we conferred the first WICGE award for Best Paper Led by a Woman.

We also conducted a global survey (not yet published) in 2016 of more than 300 coastal geoscientists worldwide on their experiences and observations of gender bias.

The results show that this is a global problem that affects daily work life and long-term career progression.

\section{CALL IT OUT}

Everyone in our network agrees that we all need to identify bias and take action. That means checking for gender equality in everything from conference committees and keynote-speaker lists to journal editorial boards and expert panels in geoscience societies, as well as in lists of peer reviewers for manuscripts and grants. We have already successfully pushed for gender balance on some conference committees and keynote-speaker line-ups. We also need to be alert to gender disparity in our own projects, papers and grant applications, and in lists of suggested reviewers when we submit a paper.

By continuing to call out gender bias and inequality, we will help to build the track records of individual female scientists and to elevate women into more-visible leadership roles in the geosciences and other disciplines.

You don't need to be a professor or in a senior position to take action. We can all make a difference. .

Shari L. Gallop is a lecturer in the Department of Environmental Sciences at Macquarie University in Sydney, Australia. 